\title{
Temor a la investigación científica
}

\author{
Fear of scientific research
}

Investigar es una acción natural que se realiza desde que el humano comenzó a razonar debido a su naturaleza de ser pensante, buscaba respuesta a lo desconocido así como a lo que le causaba curiosidad. La serie de indagaciones ha permitido llegar a disponer de las comodidades que ahora se disfruta. Para un trabajo ordenado existen criterios estandarizados con el objetivo de un mejor entendimiento universal.

Durante la Segunda Guerra Mundial se realizaron investigaciones secretas por las potencias en conflicto. Terminado el enfrentamiento los resultados se pusieron a disposición de la humanidad, no existía razón de mantenerlos en reserva por lo que comenzaron a aumentar las revistas científicas, con estándares para hablar un lenguaje científico común (1)

Los científicos peruanos de mediados del siglo pasado no se quedaron al margen, los investigadores de esa época publicaron los resultados de sus trabajos en las pocas revistas que había, quienes no contaban con ellas lo hicieron en series secuenciales que ponían a disposición de los interesados. Investigaban siguiendo el método natural, similar a como lo hicieron los investigadores clásicos en forma precisa y clara para tratar de llegar al público con lenguaje asequible.

Al producirse el boom de las publicaciones a nivel mundial, también aparecieron metodólogos en investigación científica, algunos de ellos sin haber publicado un artículo científico, eminentes teóricos, quienes empezaron a divulgar sus ideas y conceptos propios sobre el tema publicando libros sobre

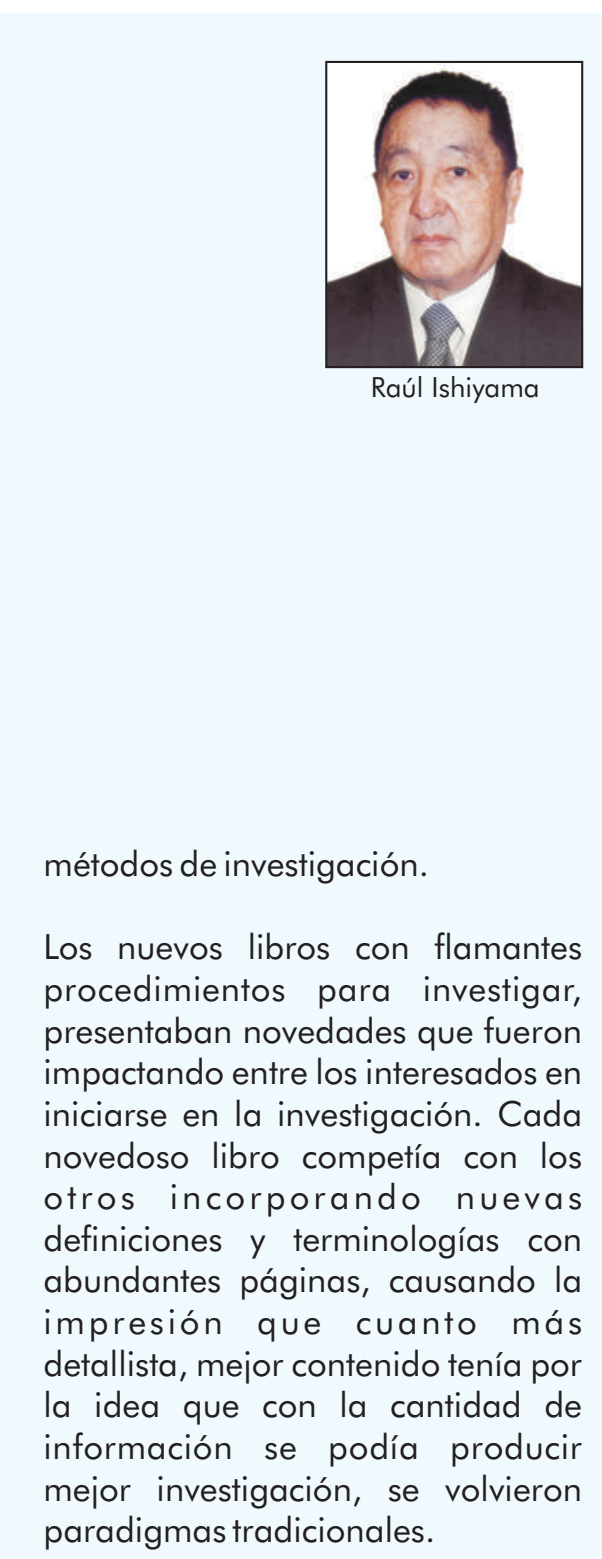


Los lectores aparentemente no se percataron que no hay dos libros sobre metodología de la investigación que se parezcan entre ellos en gran porcentaje, algunos escritos basados en la información de otros similares $y$, como se dijo, otros escritos por personas que no habían publicado alguna investigación.

A lo anterior se suma las universidades que en sus programas establecen cursos de investigación con contenidos teóricos, en algunos casos en el post grado hasta tres consecutivos. Para superar lo tedioso se inició cursos con talleres, en donde al finalizar el semestre los alumnos entregan un artículo como requisito indispensable para aprobar.

La investigación científica infunde temor debido a la complejidad en las clases que se dictan basados en el producto de la imaginación y creatividad de los autores de textos sobre el tema, cada uno emite su criterio personal a los que se suma la inspiración del docente agregando su opinión, no su experiencia práctica. Algunos métodos tienen carácter árido por exigir memorizar el vocabulario complicado y a veces con aplicación de fórmulas innecesarias, hay excepciones. El tiempo cambia conceptos e ideas, hay interés por parte de los jóvenes hacia la ciencia a través de la investigación, pero se encuentran con cursos teóricos en donde deben memorizar para rendir el examen con el objetivo de lograr una nota; insulsa y tediosa por la gran cantidad de definiciones, conceptos y clasificaciones, sin prácticas. (2)

Parte de los docentes que dictan el curso son personas que no han publicado investigaciones, son trasmisores de lo que dicen los libros sobre metodología de su preferencia, producto de la opinión, idea y creatividad del autor. Frecuentemente repitan "tal autor dice...", sin considerar que ese autor ha volcado sus ideas en el libro como opinión personal, está en su derecho por la libertad de expresión; no consideran que existen estándares propio del mundo globalizado.

Se debe promover la investigación incentivando el placer que produce obtener logros de la indagación, su inicio es un proceso agradable cuando por la sencillez se le entiende, causando satisfacción en el autor al difundir los resultados para que sean utilizados por la sociedad aplicada a la tecnología.

Investigador es la persona que investiga y publica para que se difundan sus logros, no aquel que presenta resúmenes de ponencias en eventos científicos sin respaldo real de la investigación, acumulando constancias de participación con las que se autodenomina investigador.

Para contribuir con el desarrollo se debe compartir los conocimientos, de tal manera que se beneficie la mayor parte de la población local, nacional y de ser posible mundial, en forma directa o indirecta; generando además, debates públicos sobre las decisiones de salud, alimentación, energía, ambiente, transporte y natalidad principalmente, con primacía a la más urgente; sin descuidar el proceso de investigar por investigar que genera la ciencia y la investigación básica. (3)

La cultura científica y la tecnología implican modificación sustancial entre las relaciones de los individuos con la ciencia y la tecnología, que constituye el motor del desarrollo social y económico modificando positivamente la vida cotidiana. Parte de la población piensa que esto no les concierne, que es tarea de los especialistas. Los científicos y los profesionales en general cuanto más conocimiento producen son más competitivos en su especialidad mejorando la salud, la alimentación y la comodidad de preferencia.

Un curso dictado en forma teórica no tiene significación en la vida futura del alumno como investigador. Existen docentes interesados introducir innovaciones prácticas funcionales, poco se hace en un sistema en donde cada universidad y en algunos casos cada facultad tiene su propio reglamento, pauta, norma o guía de investigación que no coincide con los estándares establecidos que permite hablar 
un lenguaje común. El uso del lenguaje y el modelo científico estandarizados tienen el objetivo propio del mundo globalizado que está tratando de superar las diferencias de idiomas, países y políticas con el fin de un entendimiento universal.

Ahora es más fácil el acercamiento de la ciencia hacia la sociedad, gracias o los diferentes medios de comunicación como revistas, televisión e Internet principalmen$\mathrm{Te}$, se ven aspectos atractivos impactantes y espectaculares preparados por técnicos especializados en ciencias, que hacen la información científica más atractiva.

La ciencia aporta conocimientos que conducen a la humanidad hacia un mejor porvenir con comodidad, la investigación con trabajo práctico es atractivo para quien se inicia en la tarea de aprender a investigar investigando, con procesos sencillos sobre la realidad, dejando que las cosas complejas se investiguen en los países del Primer Mundo que cuentan con la infraestructura adecuada para luego aprovechar sus experiencias. Cuando el joven investigador le toma gusto al proceso lo considerará un entretenimiento más que un trabajo, llegando a ser un especialista.

Un curso con el cual los alumnos aprenden a investigar investigando, consiste en clases básicas sobre investigación, búsqueda de temas originales, diseño del proyecto estandarizado, desarrollo de la investigación y presentación del informe final en formato de artículo científico para ser publicado. Tiene éxito por no ser angustiante para el alumno, quien realiza una investigación y concluye con el artículo; esto permite que el estudiante encuentre placentero aprender a investigar investigando. Esta experiencia se inició en el 2008 en la Universidad Nacional del Altiplano de Puno, se dictó el curso semi presencial Producción Intelectual, se continuó en el 2010 y en el 2012. En la Universidad Alas Peruanas en el 2011 y en la Escuela de Enfermería San Felipe el 2011 y 2012.
El curso está estructurado con el objetivo que al finalizar los estudiantes hablen un mismo lenguaje en investigación científica y entreguen un artículo. Para desarrollar la investigación se forman grupos de dos personas. Las clases presenciales son cuatro durante el semestre con talleres virtuales semanales. En la clase presencial inaugural se explica la importancia de la investigación científica, como encontrar temas originales, el diseño del proyecto estandarizado y como escribir las referencias bibliográficas; los alumnos semanalmente envían el diseño del proyecto sobre el tema que van a investigar vía Internet, son revisados y devueltos a los autores en un plazo preestablecido. Una segunda sesión presencial en donde se explica como desarrollar la investigación y el diseño del cuaderno de campo en donde van anotar los resultados; como en el caso anterior enviados semanalmente. La tercera sesión consiste en explicar como escribir el artículo científico utilizando los resultados de la investigación que figura en el cuaderno de campo que también se envía semanalmente. En la cuarta sesión se revisan los artículos con todos los alumnos y se toma el examen sobre lo que han realizado. A medida que se va desarrollando el curso se remite a los alumnos, artículos que tienen relación con el desarrollo de la investigación (3) En cada sesión se complementa con temas relacionados.

La investigación científica se aprende investigando, sin descuidar las clases teóricas indispensables y aplicables al proceso, siguiendo el ejemplo de los investigadores clásicos que no tuvieron que aprender conceptos que años después crearon los autores de libros sobre métodos de investigación. No se aprende memorizando definiciones ni diseñando cuadros complicados, se aprende practicando. Para manejar un automóvil no se requiere conocer previamente todos los componentes del motor del vehículo, similar a las complicadas clases teóricas; se aprende a conducir practicando, similar a aprender a investigar investigando. 
Enseñar y aprender ciencias es un proceso de comunicación entre alumno, profesor y compañeros. La persona aprende el lenguaje de las ciencias hablando ciencia, así como el lenguaje de la investigación haciendo investigación, estableciendo diálogo con el profesor y comunicándose con sus colegas, más adelante con sus lectores. No es suficiente leer, escuchar y discutir sino que además se debe practicar haciendo la investigación, con un lenguaje sencillo y común asequible para todos (4) La ciencia se ha desarrollado gracias que a través de los siglos las personas y los grupos interesados han ido explicando lo que es el mundo y sus fenómenos, así como logrando comodidades para sus habitantes, también elementos de destrucción. La comunicación estandarizada es vital. 


\section{REFERENCIAS BIBLIOGRAFICAS}

1. Escudero T. Desde los test hasta la investigación evaluativa actual. Un siglo, el XX, de intenso desarrollo de la evaluación en educación. RELIEVE. 2003; 9(1): 11-43.

2. Vargas-Quesada B, Moya-Anegón F, Chinchilla-Rodríguez Z, Corera-Alvarez E, GuerreroBote V. Evolución de la estructura científica española; ISI web of Science 1990-2005. El Profesional de la Información. 2008 enero-febrero; 17(1): 22-37.

3. Ishiyama R. La investigación científica y su difusión. Apuntes de Ciencia \& Sociedad. 2011 : $1(1): 73-78$.

4. Goméz-Moliné M, Sanmartí N. Reflexiones sobre el lenguaje de la ciencia y el aprendizaje. Educación Química. 2000; 11 (2): 266-273.

Correo electrónico:

raishiyama@yahoo.com 